\title{
System dynamics comparison of three inventory management models in an automotive parts supply chain
}

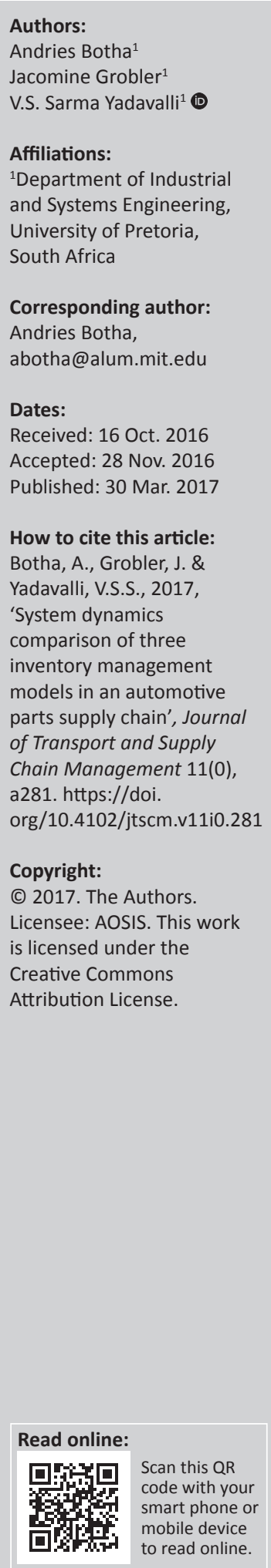

Background: The automotive parts supply chain measures its success in terms of parts availability and stock required to achieve the availability target, measured as allocation fill rate (AFR). The supply chain strives to achieve an AFR target of 95.5\% while maintaining low levels of stock.

Objective: The first objective of this study is to evaluate the current inventory management approach, namely the maximum inventory position (MIP) method, to understand the difference between the theoretical derivation and the actual implementation. The second objective is to develop and compare the performance of a new stock target setting (STS) method relative to the MIP methods.

Method: The theoretical and actual equations behind the MIP and STS methods are derived for steady state as well as stochastic conditions. A system dynamics simulation model (SDSM) was developed to describe both the local and imported supply chains. The SDSM was used to simulate and confirm the parameters for the STS method. It was also used to compare the three inventory management methods against a theoretical environment and actual data sets.

Results: The STS method requires a damping factor (DF) to ensure it does not cause the bullwhip effect. The SDSM was used to determine that a value equal to the lead time ensures effective damping. In the theoretical environment, the $\mathrm{MIP}_{\text {Theory }}$ method requires the lowest stock, but also has the lowest AFR. MIP ${ }_{\text {Actual }}$ achieves the highest AFR, but with significantly higher stock holding. The STS method improves on the AFR achieved by the MIP $\mathrm{M}_{\text {Theory }}$ method, with lower stock holding than the $\mathrm{MIP}_{\text {Actual }}$ method. With the actual demand data sets, the results vary by parts movement type. With fast moving parts, all methods achieve the AFR

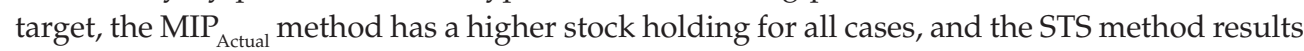
in reduced stock holding for 7 of 12 cases. With medium moving parts, the MIP $_{\text {Actual }}$ method improves on the AFR in all 15 cases, but with significantly higher stock. The STS method increases the AFR in 7 of 15 cases and reduces the stockholding in 11 of 15 cases. With slow

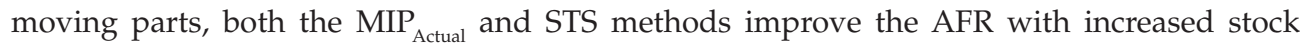
holding. The increase in stock holding for the STS method is significantly lower. With erratic moving parts, the MIP ${ }_{\text {Actual }}$ method improves on the AFR in all 17 cases, but requires significantly higher stock holding. The STS method achieves lower AFR values in 10 of 17 cases, but also requires lower or equal stock holding in 10 of 17 cases.

Conclusion: The STS method provides a new approach to inventory management in the automotive supply chain. It provides improved performance for lower stock holding than the implemented MIP method (MIP Actual $_{1}$ ). The results for the different movement category suggest that there is further research to be done to confirm the effectiveness of the various methods with other demand distributions.

\section{Introduction}

The automotive parts supply chain is unique and complex. Operating in parallel to the vehicle manufacturing supply chain, it is designed to support vehicles with both local and imported parts throughout their full life cycle, both as a current production model, as well as after the vehicle's production period. The supply chain needs to ensure parts are available to service vehicles, repair mechanical failures and damages, and perform vehicle enhancement. Demand for service parts tends to be predictable, but still exhibits significant demand variance (high average demand and high variance). Demand for parts to repair mechanical failures and damages is highly variable and erratic (low average demand and high variance). Performance of the automotive parts supply 
chain is not driven by cost, but rather by availability of a wide variety of parts. The objective of inventory optimisation is to maximise the parts availability while minimising the number of pieces in stock. The automotive industry focuses on just in time (JIT) or lean manufacturing, and the economic order quantity ordering method is not used. A standard method applied in the industry is the so-called maximum inventory position (MIP) method. The MIP method considers both the stock on hand at the distribution centre and the stock on order to calculate new orders.

The most fundamental issue in supply chain management is service to the customer. Holweg and Pil (2001) supported build-to-order supply chains, whereas Gattorna (2010) used segmentation to identify alternative supply chain designs to maximise customer service by segment. The guaranteed service (GS) model developed by Humair and Willems (2006) requires that each node in the supply chain network promises $100 \%$ delivery to the customer within the promised lead time. Based on this model, the placement of safety stock throughout the supply chain network can be calculated using a multiechelon approach. Bossert and Willems (2007) and Neale and Willems (2009) investigated the implications of the GS model for various demand conditions. Humair and Willems (2006, 2011) and Graves and Willems (2008) developed improved methods to solve the GS model algorithm to optimise the location of safety stock throughout the supply chain. Case studies applying the GS model are provided by Billington et al. (2004), Farasyn et al. (2011), Wieland et al. (2012) and Manary and Willems (2008). Owing to the mix of parts in the automotive supply chain, as mentioned earlier, it is not possible to maintain a $100 \%$ GS rate. Based on the parts demand mix, the target is arbitrarily set at a $95.5 \%$ service rate.

JIT manufacturing has had a positive impact for many firms (Lambert 2008). By reducing waste, costs are reduced and profitability increased. Lambert (2008) provided an overview of JIT thinking in the supply chain management space. The concept of 'waste' is extended to include waste specific to the supply chain, such as ineffective coordination and misalignment across functions. One of the key wastes identified in the Toyota Production System is the waste of overproduction (Shingo 1981). Reducing overproduction waste simply translates to only producing what is required. In parts supply, this translates to placing daily orders based on daily sales.

Patterson, Fredenhall and Kennedy (2002) focused on the spare parts supply chain, indicating that supply chain models should assist the practitioner to decide: When to place the order, how much to order and the impact of cost versus availability. Van der Heijden, Van Harten and De SmidtDestombes (2009) and Van der Heijden, Van Harten and De Smidt-Destombes (2006) analysed the problem of spare parts supply in the defence systems environment where both spare and repair parts supply are taken into account.

A number of authors proposed the use of simulation to analyse and optimise supply chains. Sahay and Ierapetriou
(2013) evaluated the interaction between simulation and optimisation requiring an active feedback loop between each solution. Umeda and Zhang (2008) applied a hybrid of discrete simulation, control models and system dynamics to solve supply chain problems. Tako and Robinson (2012) applied a combination of discrete event simulation and system dynamics to the supply chain. Angerhofer and Angelides (2000) and Akkermans and Dellaert (2005) provided extensive overviews of the use of system dynamics for addressing supply chain issues. System dynamics has been applied in many industries to evaluate and solve supply chain issues. Vlachos, Georgiadis and Iakovou (2007) applied system dynamics simulation for capacity planning in a closed-loop supply chain; Canella et al. (2015) focused on a coordinated decentralised supply chain, whereas Minegishi and Thiel (2000) and Georgiadis, Vlachos and Iakovou (2005) focused on applying system dynamics simulation in the food supply chain. Huang et al. (2007) applied system dynamics simulation to a so-called constant work in process controlled supply chain for lamps. In this article, system dynamics is applied to the automotive parts supply chain that operates according to a JIT approach. The purpose of this study is to evaluate three alternative inventory management strategies to achieve or exceed the allocation fill rate (AFR) target, while minimising the total number of pieces stored, using a system dynamics simulation model.

\section{Problem description}

The automotive parts supply chain has two key performance metrics, namely:

- AFR measuring the availability of parts when orders are placed.

- Pieces of stock in inventory consisting of many different parts (automotive parts stock keeping units) stored in sufficient quantities to support demand and demand variance.

The second metric is required because of space constraints. Parts can be small or large in size with low or high quantities of pieces stored as per individual part demand. Given the number of different sizes and quantities, it is not feasible to consider individual part space requirements, but with the total volume. A single inventory management model is, therefore, used for all parts.

Because applying system dynamics to supply chain research is ongoing, the objective of the study is to understand and improve on inventory management in the automotive parts business, where different demand patterns exist and supply rate is critical. Additional complexity in the industry is that space is a constraint and the bullwhip effect (Forrester 1958) is difficult to address in a practical manner. The bullwhip effect is widely described. Bhattacharya and Bandyopadhyay (2011) reviewed the various causes of the bullwhip effect and included aspects such as lead time and stock ordering policy. Wikner, Towil and Naim (1991) discussed a number of possible solutions for reducing the bullwhip effect. 


\section{Research methodology}

The first activity is a detailed analysis of the theoretical base of the inventory management methods. Secondly, the three proposed inventory management models are compared with each other in a theoretical environment, using a system dynamics simulation model (SDSM). The theoretical analysis is done using a similar demand distribution. The simulation is run 50 times to ensure statistical significance and reduce bias. Each simulation run is 500 time units in length. This makes it possible to remove 200 time units to ensure that the model has stabilised and results from the stable period are used. Finally, the SDSM is used to analyse two sets of actual demand data. The data sets are a random selection of part numbers, ordered by all dealers in the network, made available for the study. Three inventory management methods are investigated. A theoretical derivation of the concept of a pipeline-based inventory method is used. This is compared to the method in practical use. The method in use results in high parts availability with high stock holding. The third method is a new development to improve performance while maintaining a lower stockholding.

The two data sets used for practical comparison of the methods covered 9 months of actual orders placed for all parts by approximately 200 dealers in the dealer network under consideration. A representative sample of the data is used, including different movement types and sources.

During the simulation runs, the initial data are discarded, as is normal with simulations. This allows stocks to build up and dynamics to stabilise (Sterman 2000). The theoretical environment is used to validate and verify the SDSM model.

\section{Inventory optimisation models}

For the purposes of this study, the focus will be on a centralised stock model, with limited use stock at dealerships and all safety stock at the distribution centre.

In a JIT supply chain, a philosophy of sell-one-buy-one is applied. This philosophy implies that the ideal order quantity is one, ordered as soon as an item is sold. This approach differs from the traditional JIT in production where production is kept constant.

Therefore:

Reorder Point $=R=1$

[Eqn 1]

Reorder Quantity $=Q=D$

where $D$ is the constant daily demand.

Pipeline stock $\left(S_{\mathrm{P}}\right)$ can be seen as all stock that has been ordered and not yet sold:

$S_{p}=S_{O H}+S_{O O}$

[Eqn 3] where $S_{O H}$ is the stock on hand and $S_{O O}$ is the stock on order.

This means that if sales are set to zero, inventory will only build up to this level and no more. Therefore:

$M I P_{\text {Theory }}=S_{p}=S_{O H}+S_{O O}$

And:

$S_{O H}=D R=D$

$S_{O O}=Q L=D L$

[Eqn 6]

where $L$ is the lead time.

Therefore:

$M I P_{\text {Theory }}=D+D L=D(1+L)$

[Eqn 7]

Up to this point, it was assumed that $D$ is constant and that there will always be sufficient stock. In a real environment, demand will be random or stochastic. Therefore, it can be stated that $D$ is a continuous random variable representing daily demand, $\mu$ is the average value of $E(D)$ and $\sigma$ is the standard deviation of $E(D)$.

$D$ will have a probability density function, namely:

$D=f(x)$

[Eqn 8]

It is also likely that lead time will be random, giving: $H$ is a continuous random variable representing daily demand, $\mu_{2}$ is the average value of $E(H)$ and $\sigma_{2}$ is the standard deviation of $E(H)$.

$H$ will have a probability density function, namely:

$H=f(y)$

[Eqn 9]

Given this, the constant demand equations can be expanded to:

$S_{O H}=\mu(L+R)+S S_{D}$

where $S S_{D}$ is the safety stock for demand variance:

$S_{O O}=\sum Q=\left(\mu_{2}+S S_{L T}\right) \mu$

where $S S_{L T}$ is the safety stock for lead time variance.

Therefore: $M I P_{\text {Theory }}=$
$\underset{S S_{D}}{\mu}(L+R)+S S_{D}+\mu\left(\mu_{2}+S S_{L T}\right)=\mu\left(L+R+\mu_{2}+S S_{L T}\right)+$
$[$ Eqn 12$]$

[Eqn 12]

If $f(x)$ and $f(y)$ are normal distributions, we can define the safety stock in terms of the service level to be achieved. To achieve 95\% service level, the safety stocks will be: 
$S S_{D}=2 \sigma R$

[Eqn 13]

$S S_{L T}=2 \sigma_{2}$

Therefore:

$M I P_{\text {Theory }}=\mu\left(L+R+\mu_{2}+2 \sigma_{2}\right)+2 \sigma R$

This leads to:

$Q=M I P_{\text {Theory }}-\left(S_{O H}+S_{O O}\right)+B O=\mu\left(L+R+\mu_{2}+2 \sigma_{2}\right)+2 \sigma R-$ $\left(S_{O H}+S_{O O}\right)+B O$

where $B O$ is the backorders.

Backorders are treated outside of standard operation and are excluded from the base order. Toyota (2003) described the implemented equation set in use as:

$M I P_{\text {Practical }}=M A D\left(O C+L+S S_{L T}+S S_{D}\right)$

[Eqn 17]

$S O Q=M A D\left(O C+L+S S_{L T}+S S_{D}\right)-\left(S_{O H}+S_{O O}\right)+B O \quad[$ Eqn 18]

where $S O Q=Q=$ stock order quantity, $M A D=$ monthly average demand -6 months moving average and $O C=$ order cycle $=R$.

MAD is calculated using a 6-month average demand to smooth day-to-day demand fluctuations and accommodate seasonal behaviour (Toyota 2003). The values for safety stock are calculated by the inventory management system.

If Equations 16 and 18 are compared, there is a distinct difference in the way the order quantity $Q$ is determined. The main difference is the calculation of safety stock for demand $-\mathrm{SS}_{\mathrm{D}}$. In the theoretical derivation (Equation 16), the safety stock for demand takes the demand variance for the reorder period into account. With daily order placement, this means that the safety stock for demand is equal to the demand variance multiplied by the factor $(n)$ associated with a specific service level. This means that both the terms of the equation are consistent in their dimensions (pieces $\times$ time). In the practical application (Equation 18), the safety stock for demand is included in a single term with safety stock for lead time. Both the factors are multiplied by the demand, resulting in a term that does not have a dimensional consistency (pieces $\times$ pieces + pieces $\times$ time). It is postulated that the practical solution is an attempt to improve the stock availability. The result of using Equation 18 would be an increase in service level, but it would also increase stockholding significantly.

As an alternative to the MIP method, this article proposes the stock target setting (STS) method. The MIP method focuses on stock in the complete pipeline $\left(S_{\mathrm{OH}}\right.$ and $\left.S_{\mathrm{OO}}\right)$, but does not specify location at which safety stock needs to be held. As long as the total stock in the system is equal to the MIP, no additional action is taken. The proposed STS method will focus on stock on hand. It will set a target for the stock on hand, which will include safety stock for demand and lead time variance, and focus on ensuring that this target stock level is maintained. In the STS method developed for this article, one of the key activities is to ensure that the STS decision algorithm will not be the cause of the bullwhip effect. With the variance shown in the demand data, the bullwhip effect is evident even in the single stockholding environment under review.

In the STS method, two equations are required. Firstly, the order to be placed needs to be calculated:

$Q=(D-B O)+\left(T_{S}-S_{O H}\right) / D F$

[Eqn 19]

where $T_{S}$ is the stock target and $D F$ is the damping factor.

Similar to the $M I P_{\text {Theory }}$ and $M I P_{\text {Actual }}$ methods, backorders will be treated as having a secondary supply approach and they can therefore be subtracted from the demand. Any correction in the $\left(T_{S}-S_{O H}\right)$ term should result in the bullwhip effect unless the $D F$ is included.

The second equation focuses on how to set the target stock level:

$T_{S}=($ Delivery Cycle $) D$

[Eqn 20]

As shown here, Equation 20 assumes stable demand and can once again be expanded to compensate for stochastic conditions, resulting in:

$T_{S}=\left(\right.$ Delivery Cycle $\left.+2 \sigma_{2}\right)(D+2 \sigma)$

[Eqn 21]

\section{System dynamics simulation model}

An SDSM is used to compare the theoretical MIP ${ }_{\text {Theory }}$ method,

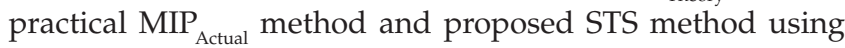
AFR and the number of pieces of inventory carried as measure. The SDSM makes it possible to use both a set of theoretical conditions and real data to compare the three methods. The SDSM reflects both imported and local suppliers, with the appropriate parameters.

The model was deliberately designed to separate information and physical flows, which have in the past been simulated as single flows, resulting in outcomes that have to be questioned. Examples include Torres and Morán (2006) and Sterman (2000:669). If the limitations in design and application domain are not fully understood, such models can provide misleading results.

The basic supply chain starts with the receipt of an order. If there is stock, the order is supplied and the stock adjusted. The inventory system will validate the received order against the system information. If the stock is available according to the inventory management system, the stock is allocated on the system. The order is then supplied from the physical stock, 
with a delay resulting from the process of supply. Once the order has been confirmed as supplied, the system stock is adjusted. The inventory management system will calculate and place an order on the supplier. If there is no stock available, the inventory management system will automatically create a backorder and place a priority order on the supplier. The supplier has a specific lead time after which the order reaches the receiving process. As orders are supplied from the supplier, the receiving process places the physical stock and updates the system stock. If the system has stock to allocate, the AFR score is one else it is zero. This provides a cumulative score of how many orders can be satisfied from system stock. A causal loop diagram of the supply chain management system, including feedback loops, is shown in Figure 1.

SDSM is constructed using a language of stock and flows to represent the series of differential equations that make up the model description. The simulation language used for this model is iThink ${ }^{\circledR}$ from iseesystems Inc. iThink ${ }^{\circledR}$ is one of a number of object-orientated simulation languages specifically designed to develop SDSM. The problem investigated will be split into two main areas, namely: import suppliers and local suppliers. Imported parts suppliers receive and process orders daily, but ship weekly with an order lead time of 63 days, whereas local part suppliers ship daily with lead times of either 7 days or 28 days (Table 1 ).

The scope of the SDSM is limited to a two-tier supply chain. Parts are ordered by dealers (dealer demand) and supplied

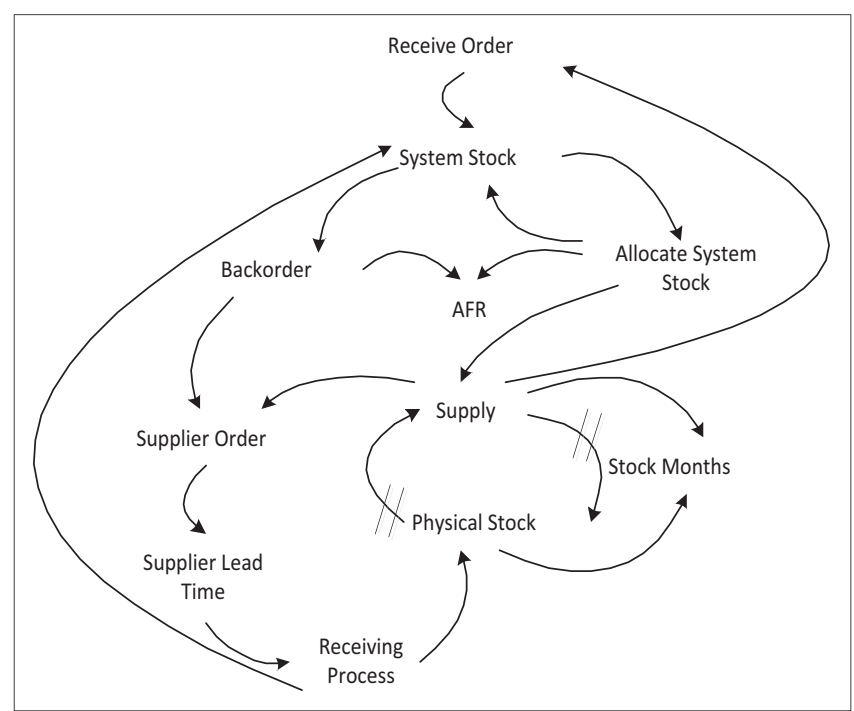

FIGURE 1: Comprehensive view of the supply chain, including supplier.

TABLE 1: Differences in factors for local and imported parts suppliers.

\begin{tabular}{lll}
\hline Factor & Local parts supplier & Imported parts supplier \\
\hline Supply lead time & $\begin{array}{l}7 \text { days for current model and high } \\
\text { volume past model parts, 28 days } \\
\text { for past model parts }\end{array}$ & 63 days for all parts \\
Shipping cycle & Daily shipping & $\begin{array}{l}\text { Pick daily but consolidate } \\
\text { weekly for shipping }\end{array}$ \\
BO & Normal shipping & $\begin{array}{l}\text { Can be sent by airfreight } \\
(7-14 \text { days })\end{array}$ \\
\hline
\end{tabular}

Source: Toyota Parts Business Report 2015, Internal Report prepared by Customer Service Division

$\mathrm{BO}$, backorders. from a distribution centre. The distribution centre then places an order on the supplier to supply within the agreed lead time. The focus of the analysis is the decision algorithm used at the distribution centre. Two simulation models were built. The first model is used to analyse the performance of the supply chain for imported parts, and the second is to analyse the performance of the supply chain for local parts. The models are used for both the theoretical analysis and the case study, where real order data will be analysed. The major difference between the two models is the shipping cycle. In the local environment, orders are placed daily and delivered daily with a 7-day lead time. In the import model, orders are placed daily, parts are picked daily, but shipping only occurs every 7th day, with a 63-day lead time from the day of shipping.

The structure of the model focuses on three parallel flow systems, namely: (1) physical flow of parts, (2) information flow and (3) backorder flow. The physical flow of parts describes the dispatch of parts from the supplier as well as the distribution centre. The backorder flow also reflects a physical flow and is required as backorders are treated separately in an attempt to limit the bullwhip effect. The information flow is required to manage data to support the order algorithm and the calculation of the AFR. The stock availability will be extracted directly from the physical parts flow section of the model.

There are a number of key simplifications and assumptions made in the model. The fundamental assumptions are as follows:

- Suppliers have sufficient capacity to accommodate the orders placed.

- Orders are placed to the supplier system on a continuous basis.

- Initial stock in the physical system will be allocated using lead time and demand.

- $L$ and $D$ can be set as a constant or as a distribution function.

- $B O$ lead time is fixed.

Both models will be used to test the three different order algorithms under investigation. The theoretical and actual implementation of the MIP models are virtually identical, with only the order algorithm being different as shown in Equations 16 and 18. The STS method will require $T_{S}$ to be determined.

Appendix 1 shows the import supplier model as a set up for the MIP algorithms. The domestic model does not include the order accumulation structure. It is necessary to include the imported supplier structure as this adds an additional dimension to the process time variance in that although orders are placed daily, they are only shipped once a week.

\section{Results and discussion}

All SDSMs were run for 500 periods and repeated 50 times. The first 200 data points were removed to allow the model 
time to stabilise. All comparisons will be based on the AFR and physical pieces of stock in inventory. Although sufficient stock must be kept to ensure that the AFR remains high, high stock levels with a low AFR is unacceptable. Low stock levels and a high AFR are ideal.

The first simulation was used to establish the DF required for the most effective operation of the STS method. It is postulated that $D F$ can be used to reduce the demand amplification in the supply chain. A demand data stream was generated using a normal distribution with an average demand of 100 units per day and a standard deviation of 10. In each case, a series of $D F$ s were selected, starting at 1 day and ending at the specific $L$. Using a $D F$ equal to the specific $L$ provides the most effective AFR and stock position (Table 2).

When $D F$ is set to 1 for imported supplier parts, the stock value overshadows the results for other values of $D F$
(Figure 2a and c). Removing DF equal to 1 clearly shows how increasing $D F$ results in a smoothing of the daily stock holding (Figure $2 \mathrm{~b}$ and $\mathrm{d}$ ). Once $D F$ reaches the lead time of 63 days, the improvements are minimal.

Increasing the DF for domestic suppliers producing parts with a 7-day lead time reduces the bullwhip effect by reducing stock and increasing AFR (Figure 3).

Increasing the $D F$ for domestic suppliers producing parts with a 28-day lead time shows results similar (increased stock) to the import model when DF is equal to 1 (Figure $4 \mathrm{a}$ and b). When $D F$ equal to 1 is removed, the reduction in the bullwhip effect can be seen clearly, with the best results when $D F$ equals $L$ (Figure 4c).

The results indicate that the ideal $D F$ can be set equal to L. For simplicity, all further STSM analysis will use a $D F$ equal to $L$.

TABLE 2: Allocation fill rate and stock results simulation of damping factor analysis for the stock target setting method for imported and domestic supplier.

\begin{tabular}{|c|c|c|c|c|c|c|c|c|c|c|}
\hline \multirow[t]{2}{*}{ Supplier } & \multicolumn{10}{|c|}{ Damping factor } \\
\hline & 1 day & 3 days & 7 days & $\begin{array}{l}7 \text { days } \\
\text { (lead time) }\end{array}$ & 14 days & 15 days & $\begin{array}{l}28 \text { days } \\
\text { (lead time) }\end{array}$ & 30 days & $\begin{array}{l}63 \text { days } \\
\text { (lead time) }\end{array}$ & $\begin{array}{l}70 \text { days (lead time + } \\
\text { shipping cycle) }\end{array}$ \\
\hline \multicolumn{11}{|l|}{ Import supplier } \\
\hline Average AFR & 90.6 & - & - & - & - & 84.6 & - & 98.5 & 99.9 & 99.9 \\
\hline Average stock & 21195.0 & - & - & - & - & 861.0 & - & 815.0 & 761.0 & 755.0 \\
\hline \multicolumn{11}{|c|}{ Domestic supplier - current } \\
\hline Average AFR & 76.9 & 93.2 & - & 100.0 & - & - & - & - & - & - \\
\hline Average stock & 177.0 & 120.0 & - & 120.0 & - & - & - & - & - & - \\
\hline \multicolumn{11}{|c|}{ Domestic supplier - past } \\
\hline Average AFR & 60.3 & - & 93.5 & - & 99.2 & - & 100.0 & - & - & - \\
\hline Average stock & 249.0 & - & 123.0 & - & 119 & - & 121.0 & - & - & - \\
\hline
\end{tabular}

AFR, allocation fill rate.

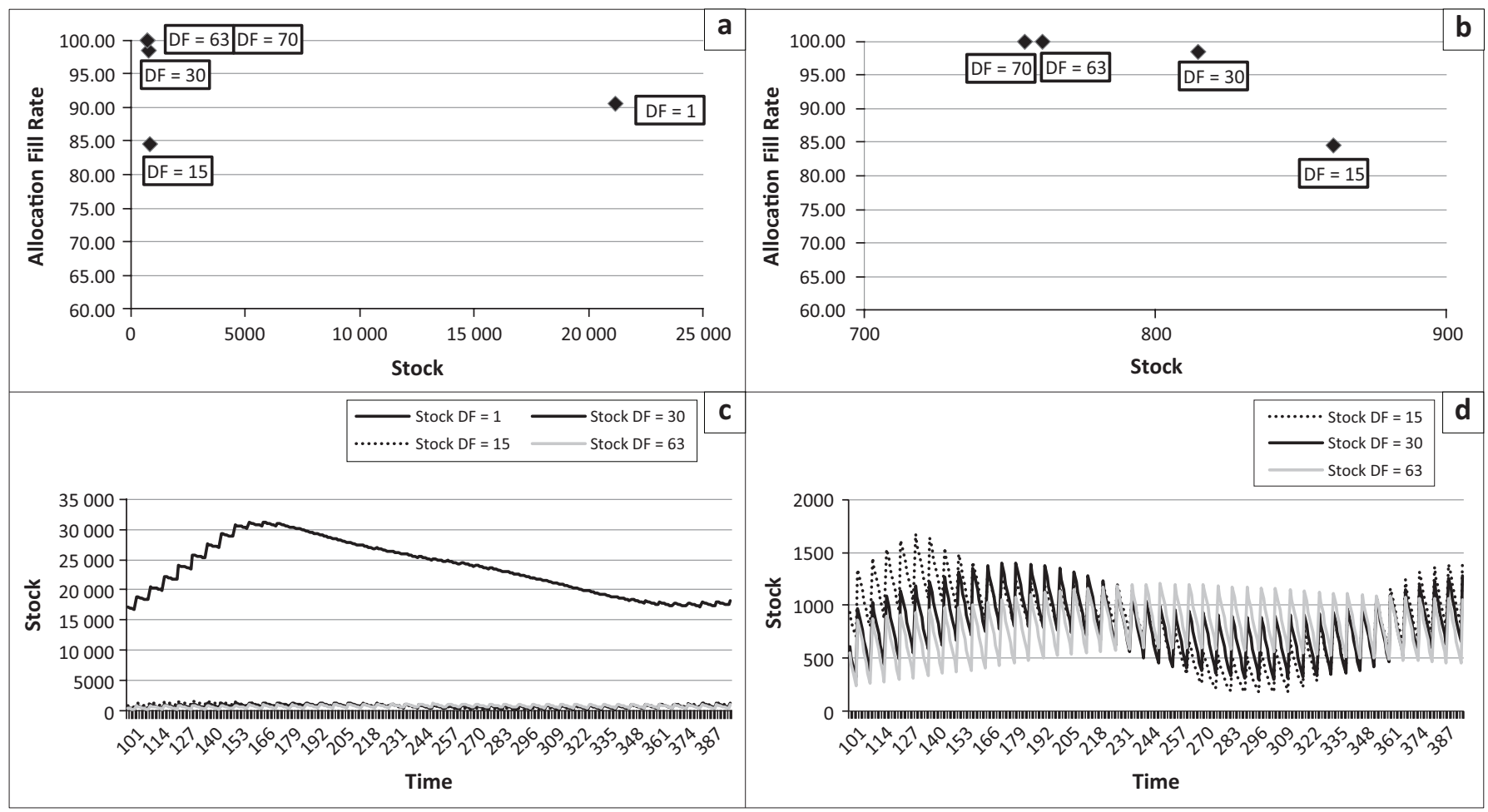

FIGURE 2: Impact of the damping factor on import supplier supply chain, where (a and c) damping factor is set to 1 for imported supplier parts and (b and d) removing damping factor equal to 1 . 


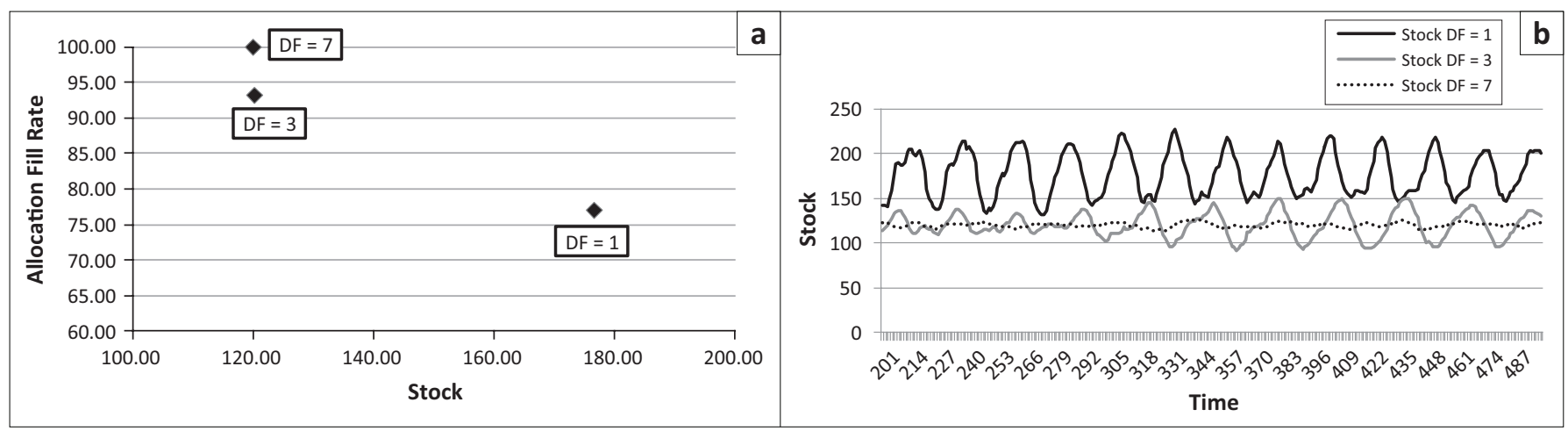

FIGURE 3: ( $a$ and b) Impact of the damping factor on a current model domestic supplier supply chain.

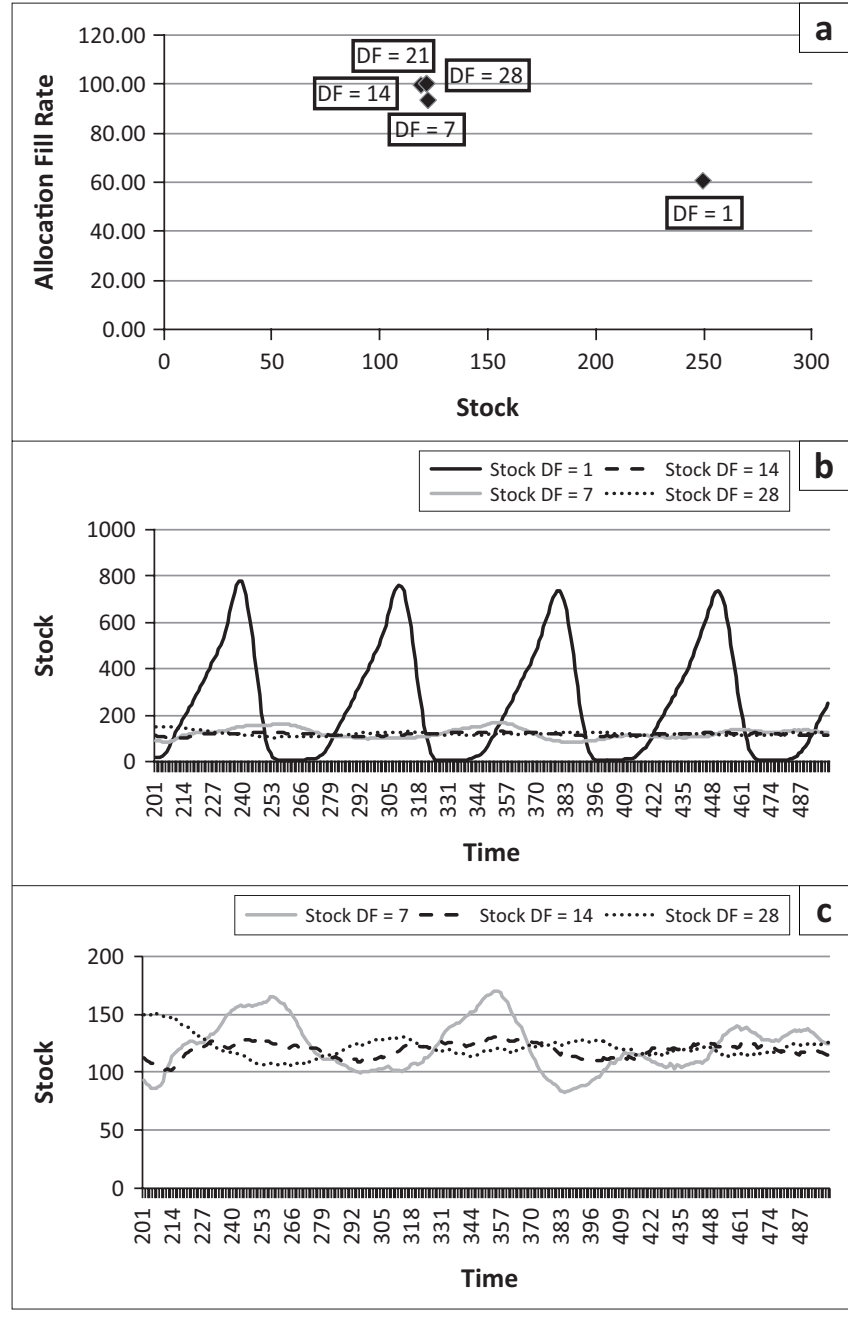

FIGURE 4: Impact of the damping factor on a past model local supplier supply chain where damping factor is ( $a$ and $b$ ) equal to 1 and (c) when damping factor equal to 1 is removed.

Next, the three methods will be compared using a theoretical environment of demand and demand variance. In the theoretical environment, a demand data stream is generated using a normal distribution with an average demand of 100 units per day and a standard deviation of 10 .

In the theoretical environment, the $M I P_{\text {Theory }}$ method requires the lowest stock amounts, but also results in the lowest AFR. In contrast, the $M I P_{\text {Actual }}$ method results in the highest AFR, but also significantly higher stock amounts (Table 3 and Figure 5). The improved AFR would confirm the reasoning behind the way the method is implemented. Given that customer service is more important, the calculation was adapted to allow for a better AFR. The unintended consequence of this was that stock holding has been increased significantly. The STS method provides a similar AFR than the $M I P_{\text {Actual }}$ method (identical in two of three cases) with significantly less stock required.

From the above results, it is clear that in the case of the local supply chains, the STS method has merits as a replacement method that will increase the AFR, but will require less stock than the $M I P_{\text {Actual }}$ method.

The final comparison between the three order placement algorithms will focus on two selected data sets. Data set one represents the demand for fast moving parts, and data set two represents the demand for erratic moving parts.

The data sets consist of the following:

- Fast (daily) moving imported parts.

- Medium (weekly) and slow (monthly) moving import parts.

- Slow (monthly) moving local parts.

- Erratic (one sale in 6 months) moving local parts.

Running the simulation for the fast moving parts, in all cases, for all three methods, results in 100\% AFR. In 8 of 12 parts investigated, the STS method required lower stock levels. In all cases, the $M I P_{\text {Actual }}$ method required significant higher stock levels (Table 4).

Running the simulation for medium and slow moving imported parts shows that in all cases, the $M I P_{\text {Actual }}$ method resulted in a $100 \%$ AFR, with increased stock holding. The STS method showed an improvement in AFR in 1 of 15 cases and a reduction in 8 of 15 cases. The stock holding increase for the improved AFR was lower than the $M I P_{\text {Actual }}$ method. In 11 of 15 cases, the stock holding required was lower than the $M I P_{\text {Theory }}$ method. Of these, four parts achieved the same or better AFR with lower stock holding. The results show that the $M I P_{\text {Actual }}$ method improves the AFR, but at a significant 
TABLE 3: Simulation results comparing the three order methods in a theoretical environment.

\begin{tabular}{|c|c|c|c|c|c|c|c|c|c|}
\hline \multirow{2}{*}{$\begin{array}{l}\text { Model: } \\
\text { algorithm }\end{array}$} & \multicolumn{3}{|c|}{ Import } & \multicolumn{3}{|c|}{ Local current } & \multicolumn{3}{|c|}{ Local past } \\
\hline & MIP theory & MIP actual & Stock target & MIP theory & MIP actual & Stock target & MIP theory & MIP actual & Stock target \\
\hline AFR $(\%)$ & 99.78 & 100.00 & 99.85 & 99.85 & 100.00 & 100.00 & 99.75 & 100.00 & 100.00 \\
\hline Stock & 339.00 & 2297.00 & 761.00 & 21.00 & 1999.00 & 120.00 & 30.00 & 2001.00 & 121.00 \\
\hline AFR change $(\%)$ & - & 0.22 & 0.07 & - & 0.15 & 0.15 & - & 0.25 & 0.25 \\
\hline Stock change & - & 6.80 & 2.20 & - & 93.20 & 5.60 & - & 66.30 & 4.00 \\
\hline
\end{tabular}

AFR, allocation fill rate; MIP, maximum inventory position.

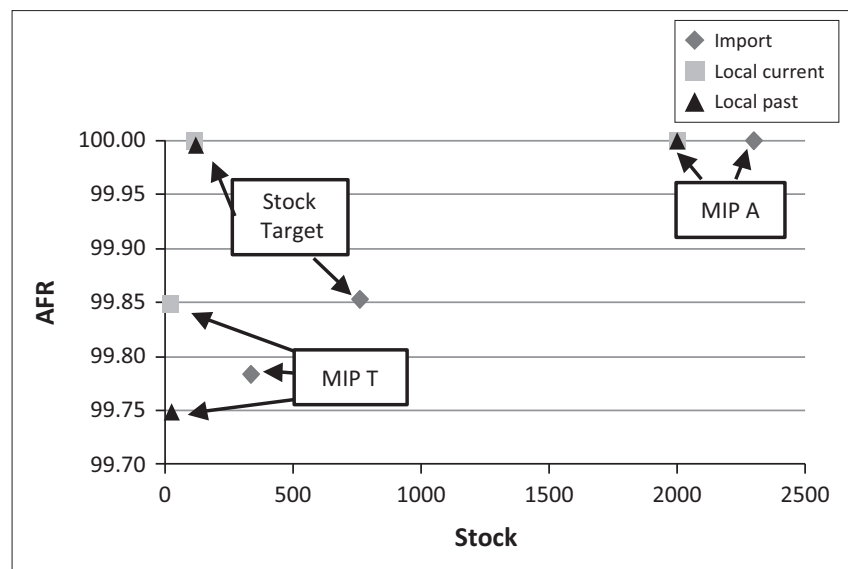

AFR, allocation fill rate; MIP, maximum inventory position.

FIGURE 5: Comparison of the three order methods in a theoretical environment.

increase in stock holding. The STS and MIP $P_{\text {Theory }}$ method achieves similar results with lower stock holding (Table 5).

Running the simulation for slow moving local parts shows that in all cases, the MIP $P_{\text {Actual }}$ method improves the AFR, but with stock holding increased by four times. The STS method also improves on the AFR in all cases. It also requires stock holding to be increased, but in only two cases is the stock required double that of the $M I P_{\text {Theory }}$ method. The results show that the STS method provides a better overall solution with increased AFR with the lowest stock holding (Table 6).

Running the simulation for erratic moving local parts shows that the MIP $P_{\text {Actual }}$ method improved the AFR in 15 of 16 cases, in all cases increasing the stock holding. In only three cases, the stock increase was less than double. In 7 of 16 cases, the STS method improved the AFR, whereas the other 9 cases resulted in a drop of AFR. In five cases, the stock holding was reduced. The results show that the $M I P_{\text {Actual }}$ method would provide equivalent performance to the other methods, but with the lowest stock holding (Table 7).

\section{Conclusion}

In this article, four key issues were addressed. The theory behind the MIP method and how it is implemented was analysed. The difference between the theoretical and actual implementation was identified. An alternative STS method, focusing on stock targeting, was derived theoretically. An SDSM was developed to analyse the performance of the ordering algorithms on the supply chain. The SDSM is limited in that it does not simulate a unique demand for every part, but rather a demand distribution based on a fixed set of variables. The analysis of the actual data sets is limited in that actual stock holding data are not available, and therefore, the results cannot be compared to the actual situation. The STS method was analysed to confirm that it would not result in the bullwhip effect by evaluating the impact of damping on the supply chain performance. Following the analysis, the $D F$ was set equal to $L$. The three order algorithms were compared in a theoretical environment. Under the theoretical demand distribution conditions, it was found that the MIP $P_{\text {Actual }}$ and STS algorithms increase the AFR. It was also shown that the $M I P_{\text {Actual }}$ method requires significantly higher stock holding to provide the improved AFR values. In all cases, this was in excess of 10 times more than the STS method.

Two actual data sets were used to evaluate the effectiveness of the three algorithms in practice. The results indicate that except for the fast moving imported parts, the $M I P_{\text {Theory }}$ algorithm does not provide the ideal AFR. The $M I P_{\text {Actual }}$ method improves on the AFR, but also results in a significant increase in stock holding required. The STS method, in general, provides an increase in the AFR, except for the erratic moving parts, with a lower increase in stock holding.

The results obtained at this point suggest that the STS method be further investigated as an alternative solution to the $M I P_{\text {Actual }}$ method to ensure that the warehouse space constraint is managed effectively. The effectiveness of the three methods to ensure the target AFR is achieved with the least amount of stock against various theoretical demand patterns (log-normal or gamma distributions) should be investigated to determine if the methods are applicable to specific demand patterns.

\section{Acknowledgements Competing interests}

The authors declare that they have no financial or personal relationships that may have inappropriately influenced them in writing this article.

\section{Authors' contributions}

The study forms part of A.B.'s PhD study. He proposed and developed the STS inventory management method. He constructed the SDSM for analysing the three inventory management methods. He also performed all the theoretical and actual data simulations. J.G. and V.S.S.Y. contributed as study leaders, providing direction and critical review of the article. 
TABLE 4: Results of simulating actual demand data for fast moving import parts.

\begin{tabular}{|c|c|c|c|c|c|c|c|c|c|c|}
\hline \multirow[t]{2}{*}{ Part } & \multicolumn{2}{|c|}{ MIPT } & \multicolumn{2}{|c|}{ MIPA } & \multicolumn{2}{|c|}{ Improvement } & \multicolumn{2}{|c|}{ Stock target } & \multicolumn{2}{|c|}{ Improvement } \\
\hline & $\begin{array}{l}\text { AFR } \\
(\%)\end{array}$ & $\begin{array}{l}\text { Avg } \\
\text { stock }\end{array}$ & $\begin{array}{l}\text { AFR } \\
(\%)\end{array}$ & $\begin{array}{l}\text { Avg } \\
\text { stock }\end{array}$ & $\begin{array}{l}\text { AFR } \\
\text { change }\end{array}$ & $\begin{array}{l}\text { Avg stock } \\
\text { change }\end{array}$ & $\begin{array}{l}\text { AFR } \\
(\%)\end{array}$ & $\begin{array}{l}\text { Avg } \\
\text { stock }\end{array}$ & $\begin{array}{l}\text { AFR } \\
\text { change }\end{array}$ & $\begin{array}{l}\text { Avg stock } \\
\text { change }\end{array}$ \\
\hline Part 04 & 100.00 & 1028 & 100.00 & 4772 & 0 & 3744 & 100.00 & 932 & 0 & -96 \\
\hline Part 06 & 100.00 & 179 & 100.00 & 189 & 0 & 9 & 100.00 & 155 & 0 & -25 \\
\hline Part 07 & 100.00 & 378 & 100.00 & 765 & 0 & 387 & 100.00 & 327 & 0 & -51 \\
\hline Part 08 & 100.00 & 378 & 100.00 & 782 & 0 & 404 & 100.00 & 326 & 0 & -51 \\
\hline Part 12 & 100.00 & 1438 & 100.00 & 2621 & 0 & 1184 & 100.00 & 1650 & 0 & 213 \\
\hline Part 22 & 100.00 & 552 & 100.00 & 714 & 0 & 162 & 100.00 & 515 & 0 & -37 \\
\hline Part 24 & 100.00 & 421 & 100.00 & 581 & 0 & 160 & 100.00 & 459 & 0 & 39 \\
\hline Part 25 & 100.00 & 4145 & 100.00 & 130417 & 0 & 126272 & 100.00 & 5217 & 0 & 1072 \\
\hline Part 26 & 100.00 & 963 & 100.00 & 1498 & 0 & 535 & 100.00 & 930 & 0 & -33 \\
\hline Part 28 & 100.00 & 463 & 100.00 & 577 & 0 & 114 & 100.00 & 433 & 0 & -30 \\
\hline
\end{tabular}

MIPT, MIP Theory AFR, allocation fill rate; Avg, Average; MIPA, MIP ${ }_{\text {Actual }}$.

TABLE 5: Results of simulating actual demand data for medium and slow moving import parts.

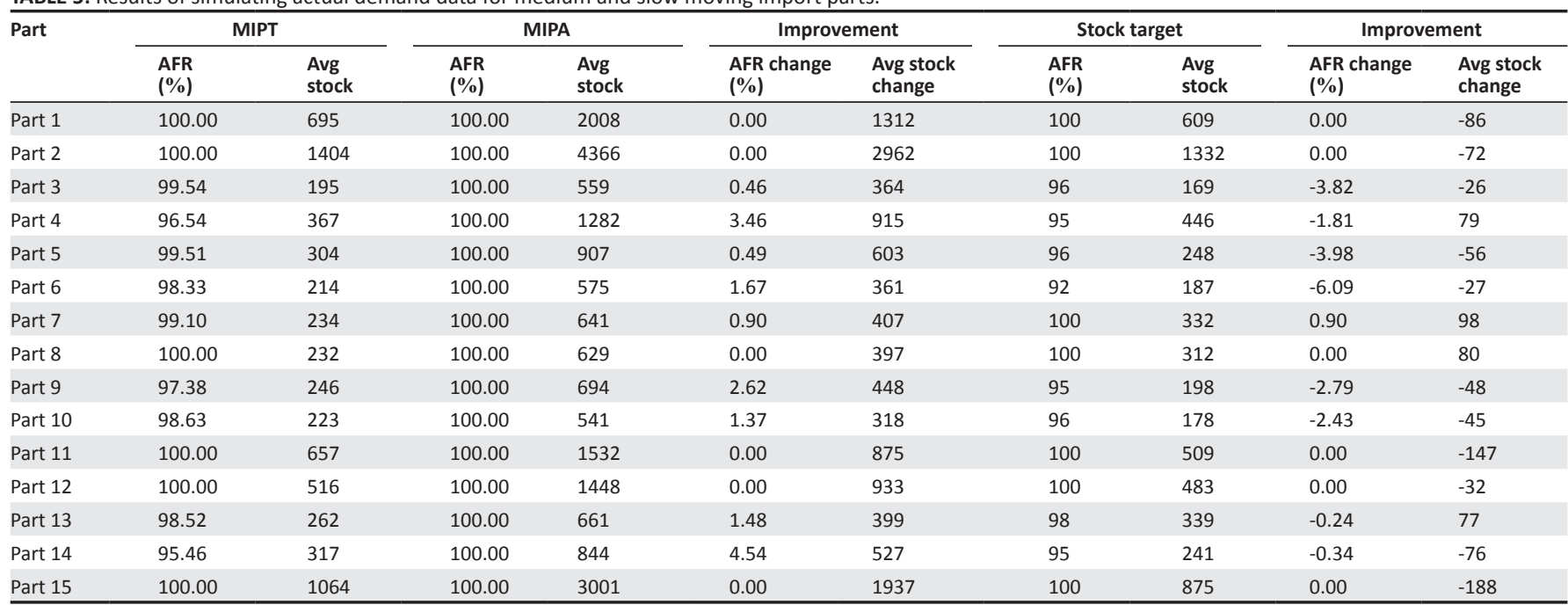

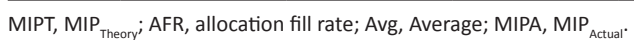

TABLE 6: Results of simulating actual demand data for slow moving local parts.

\begin{tabular}{|c|c|c|c|c|c|c|c|c|c|c|}
\hline \multirow[t]{2}{*}{ Part } & \multicolumn{2}{|c|}{ MIPT } & \multicolumn{2}{|c|}{ MIPA } & \multicolumn{2}{|c|}{ Improvement } & \multicolumn{2}{|c|}{ Stock target } & \multicolumn{2}{|c|}{ Improvement } \\
\hline & $\begin{array}{l}\text { AFR } \\
(\%)\end{array}$ & $\begin{array}{l}\text { Avg } \\
\text { stock }\end{array}$ & $\begin{array}{l}\text { AFR } \\
(\%)\end{array}$ & $\begin{array}{l}\text { Avg } \\
\text { stock }\end{array}$ & $\begin{array}{l}\text { AFR change } \\
(\%)\end{array}$ & $\begin{array}{l}\text { Avg stock } \\
\text { change }\end{array}$ & $\begin{array}{l}\text { AFR } \\
(\%)\end{array}$ & $\begin{array}{l}\text { Avg } \\
\text { stock }\end{array}$ & $\begin{array}{l}\text { AFR change } \\
(\%)\end{array}$ & $\begin{array}{l}\text { Avg stock } \\
\text { change }\end{array}$ \\
\hline Part 01 & 78.92 & 60 & 82.12 & 700 & 3.20 & 640 & 79 & 64 & 0.21 & 4 \\
\hline Part 03 & 22.53 & 279 & 23.04 & 3523 & 0.50 & 3244 & 22 & 266 & -0.26 & -13 \\
\hline Part 09 & 17.29 & 241 & 17.29 & 1757 & 0.00 & 1516 & 16 & 116 & -0.96 & -125 \\
\hline Part 10 & 9.58 & 36 & 9.83 & 56 & 0.26 & 21 & 10 & 153 & 0.26 & 118 \\
\hline Part 11 & 11.97 & 190 & 13.85 & 1203 & 1.88 & 1013 & 12 & 173 & 0.23 & -17 \\
\hline Part 13 & 81.24 & 31 & 82.63 & 188 & 1.39 & 157 & 81 & 30 & -0.52 & 0 \\
\hline Part 14 & 93.70 & 2733 & 96.78 & 2057466 & 3.08 & 2054733 & 94 & 4028 & 0.59 & 1295 \\
\hline Part 16 & 78.84 & 39 & 79.85 & 231 & 1.01 & 192 & 76 & 39 & -2.77 & 0 \\
\hline Part 17 & 82.99 & 13 & 83.83 & 36 & 0.84 & 22 & 82 & 13 & -1.16 & 0 \\
\hline Part 18 & 80.23 & 23 & 83.07 & 95 & 2.84 & 73 & 79 & 27 & -1.47 & 5 \\
\hline Part 19 & 79.35 & 20 & 82.99 & 64 & 3.64 & 45 & 79 & 20 & -0.42 & 0 \\
\hline Part 20 & 80.30 & 17 & 82.54 & 62 & 2.25 & 45 & 80 & 17 & 0.18 & 0 \\
\hline Part 23 & 75.69 & 17 & 78.82 & 46 & 3.13 & 29 & 76 & 19 & 0.27 & 2 \\
\hline Part 29 & 93.29 & 3053 & 94.13 & 3563903 & 0.83 & 3560850 & 94 & 4308 & 0.31 & 1254 \\
\hline Part 31 & 91.93 & 673 & 93.41 & 122691 & 1.48 & 122018 & 91 & 800 & -0.72 & 127 \\
\hline
\end{tabular}

$\mathrm{MIPT} \mathrm{MIP}_{\text {Theory }}$; AFR, allocation fill rate; Avg, Average; MIPA, MIP Actual 
TABLE 7: Results of simulating actual demand data for erratic moving local parts.

\begin{tabular}{|c|c|c|c|c|c|c|c|c|c|c|}
\hline \multirow[t]{2}{*}{ Part } & \multicolumn{2}{|c|}{ MIPT } & \multicolumn{2}{|c|}{ MIPA } & \multicolumn{2}{|c|}{ Improvement } & \multicolumn{2}{|c|}{ Stock Target } & \multicolumn{2}{|c|}{ Improvement } \\
\hline & AFR $(\%)$ & Avg stock & AFR $(\%)$ & Avg stock & $\begin{array}{l}\text { AFR change } \\
(\%)\end{array}$ & $\begin{array}{l}\text { Avg stock } \\
\text { change }\end{array}$ & AFR $(\%)$ & Avg stock & $\begin{array}{l}\text { AFR change } \\
(\%)\end{array}$ & $\begin{array}{l}\text { Avg stock } \\
\text { change }\end{array}$ \\
\hline Part 1 & 78.28 & 109 & 80.09 & 1326 & 1.81 & 1218 & 79.29 & 166 & 1.01 & 57 \\
\hline Part 2 & 84.81 & 55 & 87.39 & 518 & 2.58 & 463 & 86.73 & 96 & 1.93 & 41 \\
\hline Part 3 & 55.36 & 86 & 56.34 & 666 & 0.98 & 580 & 56.20 & 120 & 0.83 & 34 \\
\hline Part 4 & 81.26 & 47 & 84.09 & 471 & 2.83 & 423 & 83.79 & 92 & 2.53 & 45 \\
\hline Part 5 & 81.40 & 62 & 82.65 & 605 & 1.25 & 542 & 81.51 & 110 & 0.10 & 47 \\
\hline Part 6 & 77.83 & 62 & 82.44 & 563 & 4.61 & 501 & 80.22 & 114 & 2.39 & 51 \\
\hline Part 7 & 76.16 & 43 & 79.89 & 359 & 3.73 & 316 & 79.08 & 83 & 2.92 & 40 \\
\hline Part 8 & 84.45 & 47 & 87.02 & 534 & 2.57 & 487 & 86.92 & 96 & 2.47 & 48 \\
\hline Part 9 & 81.25 & 58 & 82.13 & 517 & 0.88 & 459 & 81.48 & 96 & 0.23 & 37 \\
\hline Part 10 & 85.47 & 47 & 86.52 & 432 & 1.05 & 385 & 86.37 & 86 & 0.90 & 39 \\
\hline Part 11 & 87.73 & 29 & 89.74 & 307 & 2.02 & 278 & 89.74 & 72 & 2.02 & 43 \\
\hline Part 12 & 78.15 & 56 & 80.22 & 463 & 2.06 & 408 & 79.19 & 91 & 1.04 & 35 \\
\hline Part 14 & 78.01 & 56 & 80.22 & 482 & 2.21 & 426 & 78.92 & 98 & 0.91 & 42 \\
\hline Part 15 & 72.42 & 97 & 74.13 & 1122 & 1.71 & 1025 & 73.13 & 159 & 0.71 & 62 \\
\hline
\end{tabular}

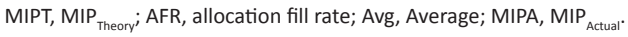

\section{References}

Akkermans, H. \& Dellaert, N., 2005, 'The rediscovery of industrial dynamics: The contribution of system dynamics to supply chain in a dynamics and fragmented world', System Dynamics Review 21(3), 173-186. https://doi.org/10.1002/sdr.317

Angerhofer, B.J. \& Angelides, M.C., 2000, 'System dynamics modelling in supply chain management: research review', in R.R. Barton, K. Kang, P.A. Fishwick \& J.A. Joines (eds.), Proceedings of the 2000 Winter Simulation Conference, 2000, Wyndham Palace Resort \& Spa, Orlando, FL, USA, December 10-13, 2000, pp. 342-350.

Bhattacharya, R. \& Bandyopadhyay, S., 2011, 'A review of the causes of bullwhip effect in a supply chain', International Journal of Manufacturing Technology 54 1245-1261. https://doi.org/10.1007/s00170-010-2987-6

Billington, C., Callioni, G., Crane, B., Rurak, J.D., Rapp, J.U., White, T. et al., 2004 'Accelerating the profitability of Hewlett-Packard's supply chains', Interfaces 34(1), 59-72. https://doi.org/10.1287/inte.0103.0054

Bossert, J.M. \& Willems, S.P., 2007, 'A periodic-review modeling approach for guaranteed service supply chains', Interfaces 37(5), 420-435. https://doi. org/10.1287/inte.1070.0298

Canella, S., Lopez-Campos, M., Dominguez, R., Ashayeri, J. \& Miranda, P.A., 2015, 'A simulation model of a coordinated decentralized supply chain', International Transaction in Operational Research 22, 735-756. https://doi.org/10.1111/ itor. 12175

Farasyn, I., Humair, S., Kahn, J.I. \& Willems, S.P., 2011, 'Inventory optimization at procter \& gamble: Achieving real benefits through user adoption of inventory tools', Interfaces 41(1), 66-78. https://doi.org/10.1287/inte.1100.0546

Forrester, J.W., 1958, 'Industrial dynamics: A major breakthrough for decision makers', Harvard Business Review 36, 37-66.

Gattorna, J.L., 2010, Dynamic supply chains - Delivering value through people, Pearson Education Limited, Edinburgh Gate, Harlow, UK.

Georgiadis, P., Vlachos, D. \& lakovou, E., 2005, 'A system dynamics modeling framework for the strategic supply chain management of food chains', Journal of Food Engineering 70, 351-364. https://doi.org/10.1016/j.jfoodeng. 2004.06.030

Graves, S.C. \& Willems, S.P., 2008, 'Strategic inventory placement in supply chains: Nonstationary demand', Manufacturing \& Service Operations Management 10(2) 278-287. https://doi.org/10.1287/msom.1070.0175

Holweg, M. \& Pil, F.K., 2001, 'Star with the customer', MIT Sloan Management Review 43(1), 74-83.

Huang, M., Ip, W.H., Yung, K.L., Wang, X. \& Wang, D., 2007, 'Simulation study using system dynamics for a CONWIP-controlled lamp supply chain', International system dynamics for a CONWIP-controlled lamp supply chain', International
Journal Advanced Manufacturing Technology 32, 184-193. https://doi. Journal Advanced Manufacturing
org/10.1007/s00170-005-0324-2

Humair, S. \& Willems, S.P., 2006, 'Optimizing strategic safety stock placement in supply chains with clusters of commonality', Operations Research 54(4), 725-742. https://doi.org/10.1287/opre.1060.0313

Humair, S. \& Willems, S.P., 2011, 'Optimizing strategic safety stock placement in general acyclic networks', Operations Research 59(3), 781-787. https://doi. org/10.1287/opre.1100.0913
Lambert, D.M., 2008, Supply chain management - Processes, partnerships, performance, Supply Chain Management Institute, Sarasota, FL.

Manary, M.P. \& Willems, S.P., 2008, 'Setting safety stock targets at Intel in the presence of forecast bias', Interfaces 38(2), 112-122. https://doi.org/10.1287/inte. 1070.0339

Minegishi, S. \& Thiel, D., 2000, 'System dynamics modeling and simulation of a particular food supply chain', Simulation Practice and Theory 8, 321-339. https:// particular food supply chain', Simulation P
doi.org/10.1016/S0928-4869(00)00026-4

Neale, J.J. \& Willems, S.P., 2009, 'Managing inventory in supply chains with nonstationary demand', Interfaces 39(5), 388-399. https://doi.org/10.1287/ inte.1090.0442

Patterson, J.W., Fredenhall, L.D. \& Kennedy, W.J., 2002, 'An overview of recent literature on spare parts inventories', International Journal of Production Economics 76, 201-215. https://doi.org/10.1016/S0925-5273(01)00174-8

Sahay, N. \& lerapetriou, M., 2013, 'Supply chain management and optimisation driven simulation approach', American Institute of Chemical Engineers 59(12) 4612-4626. https://doi.org/10.1002/aic.14226

Shingo, S., 1981, A study of the toyota production system from and industria engineering viewpoint, transl. A.P. Dillion, Productivity Press, NewYork.

Sterman, J., 2000, Business dynamics, systems thinking and modelling for a complex world, The McGraw-Hill Companies Inc, Boston.

Tako, A.A. \& Robinson, S., 2012, 'The application of discrete event simulation and system dynamics in the logistics and supply chain context', Decision Support Systems 52, 802-815. https://doi.org/10.1016/j.dss.2011.11.015

Torres, O.A.C. \& Morán, F.A.V., 2006, The Bullwhip effect in supply chains - A review of methods, components and cases, Palgrave MacMillan, New York.

Toyota, 2003, Scribd, viewed 16 May 2016 from http://www.scribd.com/doc/ 35919069/1-Inventory-Mgmt.

Umeda, S. \& Zhang, F., 2008, 'Hybrid modeling approach for supply-chain simulation', in T. Koch (ed.), International Federation for Information Processing, vol. 257, pp. 453-460, Springer, Gewerbestrasse 11, 6330 Cham, Switzerland.

Van der Heijden, K.S., Van Harten, M.C. \& De Smidt-Destombes, A., 2006, 'On the interaction between maintenance, spare parts inventories and repair capacity for a k-ou-of-N system with wear-out', European Journal of Operational Research 174 182-200. https://doi.org/10.1016/j.ejor.2005.02.043

Van der Heijden, K.S., Van Harten, M.C. \& De Smidt-Destombes, A., 2009, 'Joint optimisation of spare part inventory, maintenance frequency and repair capacity for k-out-of-N systems', International Journal of Production Economics 118 260-268. https://doi.org/10.1016/j.ijpe.2008.08.058

Vlachos, D., Georgiadis, P. \& lakovou, E., 2007, 'A system dynamics model for dynamic capacity planning of remanufacturing in closed-loop supply chains', Computers \& Operations Research 34, 367-394. https://doi.org/10.1016/j.cor.2005.03.005

Wieland, B., Mastrantonio, P., Willems, S.P. \& Kempf, K.G., 2012, 'Optimizing inventory levels within Intel's channel supply demand operations', Interfaces 42(6), 517-527. https://doi.org/10.1287/inte.1120.0637

Wikner, J., Towil, D.R. \& Naim, M., 1991, 'Smoothing supply chain dynamics', International Journal of Production Economics 22, 231-248. https://doi.org/ 10.1016/0925-5273(91)90099-F 


\section{Appendix 1}

\section{Import supplier model}

BO_Accum $(t)=$ BO_Accum $(t-d t)+\left(B O-B O \_S e n d \_t o\right) * d t$

INIT BO_Accum $=0$

DOCUMENT: Back Ordered pieces waiting for the shipment cycle.

INFLOWS:

BO = Demand-Shipped

DOCUMENT: Back Order pieces allocated for shipping. This is the difference between demand and available stock.

OUTFLOWS:

BO_Send_to $=$ if time/Shipment_Cycle=int(time/Shipment_Cycle) then BO_Accum/dt else 0

DOCUMENT: Back Order pieces loaded onto the ship for departure.

In_Stock $(\mathrm{t})=$ In_Stock $(\mathrm{t}-\mathrm{dt})+($ Arrive - Shipped $) * d t$

INIT In_Stock = Starting_Stock_Days

DOCUMENT: Inventory pieces in stock at the distribution centre.

INFLOWS:

Arrive $=$ CONVEYOR OUTFLOW

DOCUMENT: Pieces of stock arriving at the distribution centre.

OUTFLOWS:

Shipped $=$ Demand

DOCUMENT: Pieces shipped to clients.

$\mathrm{MIP}(\mathrm{t})=\mathrm{MIP}(\mathrm{t}-\mathrm{dt})+\left(\mathrm{MIP}_{-}\right.$New - MIP_Refresh $) * d t$

INIT MIP $=$ MIP_Calculation

DOCUMENT: Storing of monthly MIP review.

INFLOWS:

MIP_New $=$ if MIP_Refresh $>0$ then (MIP_Calculation)/dt else 0

DOCUMENT: Monthly MIP update - data inflow.

OUTFLOWS:

MIP_Refresh $=$ if time/28 $=$ int (time/28) then MIP/dt else 0

DOCUMENT: Monthly MIP update - data clean out.

Order_Accum $(\mathrm{t})=$ Order_Accum $(\mathrm{t}-\mathrm{dt})+($ Produced - Send_to $) * d t$

INIT Order_Accum $=0$

DOCUMENT: Processed pieces, waiting for ship departures.

INFLOWS:

Produced $=$ MIP_Based_Order

DOCUMENT: Order processing rate.

OUTFLOWS:

Send_to $=$ if time/Shipment_Cycle=int(time/Shipment_Cycle) then Order_Accum/dt else 0

DOCUMENT: Loading of pieces on ship, based on shipment cycle.

BO_en_Route $(\mathrm{t})=\mathrm{BO}$ _en_Route $(\mathrm{t}-\mathrm{dt})+\left(\mathrm{BO} \_\right.$Send_to $-\mathrm{BO} \_$Shipped $) * \mathrm{dt}$

INIT BO_en_Route $=0$

TRANSIT TIME $=1$

CAPACITY $=$ INF

INFLOW LIMIT = INF

DOCUMENT: Back Ordered pieces en route to the client.

INFLOWS:

BO_Send_to $=$ if time/Shipment_Cycle=int(time/Shipment_Cycle) then BO_Accum/dt else 0

DOCUMENT: Back Order pieces loaded onto the ship for departure.

OUTFLOWS:

BO_Shipped $=$ CONVEYOR OUTFLOW

DOCUMENT: Back Order pieces shipped to the client.

Orders_en_Route $(\mathrm{t})=$ Orders_en_Route $(\mathrm{t}-\mathrm{dt})+($ Send_to - Arrive $) * d t$

INIT Orders_en_Route $=0$

TRANSIT TIME = Order_Lead_Time

CAPACITY $=$ INF

INFLOW LIMIT = INF

DOCUMENT: Pieces of stock en route.

INFLOWS: 
Send_to $=$ if time/Shipment_Cycle=int(time/Shipment_Cycle) then Order_Accum/dt else 0

DOCUMENT: Loading of pieces on ship, based on shipment cycle.

OUTFLOWS:

Arrive $=$ CONVEYOR OUTFLOW

DOCUMENT: Pieces of stock arriving at the distribution centre.

Total_Allocation $(\mathrm{t})=$ Total_Allocation $(\mathrm{t}-\mathrm{dt})+($ Flow_1 - Flow_2 $) * d t$

INIT Total_Allocation $=0$

TRANSIT TIME $=$ Days_per_Month

CAPACITY $=$ INF

INFLOW LIMIT = INF

DOCUMENT: Consolidation of stock availability data for AFR calculation.

INFLOWS:

Flow_1 = Allocation

DOCUMENT: Allocation data inflow.

OUTFLOWS:

Flow_2 = CONVEYOR OUTFLOW

DOCUMENT: Allocation data outflow.

Allocation $=$ Shipped $/$ Demand

DOCUMENT: Immediate stock availability information.

Avg_Allocation = Total_Allocation/Days_per_Month*100

DOCUMENT: Allocation Fill Rate (AFR) calculation.

Base_Demand $=100$

DOCUMENT: Average value of the number of pieces demanded on a daily basis.

Base_Lead_Time $=63$

DOCUMENT: Average lead time.

BO_Lead_Time $=7$

DOCUMENT: Lead Time used to supply Back Orders.

Days_per_Month $=30$

DOCUMENT: Standard days per month to calculate AFR.

Demand $=$ normal(Base_Demand,Demand_Variance)

DOCUMENT: Demand in pieces calculated as a normal distribution with Base Demand as average and demand variance as the Standard Deviation - Normal(Base Demand,demand variance).

Demand_Variance $=0$

DOCUMENT: Demand variance.

MIP_Based_Order = $\max (0$, MIP-Orders_en_Route-In_Stock-BO_en_Route-Order_Accum-BO_Accum)

DOCUMENT: Order placement as per MIP method.

MIP_Calculation = Base_Demand*(Shipment_Cycle+(Order_Cycle_Days)+Base_Lead_Time+2*Order_Lead_Time_variance+2*Demand_ Variance*Base_Demand)

DOCUMENT: Calculation of MIP, based on demand, demand variance, lead time and lead time variance.

Order_Cycle_Days $=1$

DOCUMENT: The frequency of orders. For daily orders this value is set at 1 .

Order Flow $=$ Produced $+\mathrm{BO}$

DOCUMENT: Calculation for confirming total order flow is the same as demand.

Order_Lead_Time $=\max ($ Base_Lead_Time,normal(Base_Lead_Time,OOrder_Lead_Time_variance $))$

DOCUMENT: Order lead time calculated as a normal distribution of average lead time and order lead time variance.

Order_Lead_Time_variance $=0$

DOCUMENT: Order variance lead time.

Run_Counter $=50$

DOCUMENT: Dummy variable used to set the number of simulation runs to be completed.

Shipment_Cycle $=7$

DOCUMENT: Frequency of ship departures.

Starting_Stock_Days $=$ MIP_Calculation

DOCUMENT: Initial stock value.

Stock_Days = In_Stock/Demand

DOCUMENT: Calculation of Stock Coverage - Stock/Demand. 